\title{
DSC supported by factor analysis as a reliable tool for compatibility study in pharmaceutical mixtures
}

\author{
Barbara Rojek $^{1} \cdot$ Marek Wesolowski $^{1}$
}

Received: 15 November 2018/ Accepted: 25 March 2019/Published online: 2 April 2019

(c) The Author(s) 2019

\begin{abstract}
A chemometrically optimized DSC interpretation was developed for the identification of compatibility/incompatibility between active pharmaceutical ingredients (APIs) and excipients in pharmaceutical preparations. The chemometric approach based on factor analysis (FA) can be used as a supplementary tool for incompatibility detection in theophylline mixtures with excipients. The FA results expose the formation of two distinctly separate clusters on the FA score scatter plots-in the case of mixtures with compatible ingredients, one cluster was formed by theophylline and mixtures with high API content, the second by excipient and mixtures with high excipient content. In the event of incompatibility, the DSC curves of binary mixtures differ from those of ingredients, and the FA score scatter plot displays one cluster consisting of some mixtures at different ratios and the other of remaining mixtures and both ingredients. In brief, FA proved the incompatibility of theophylline mixtures with arabic gum, glucose, sorbitol and sucrose. The application of FA can help to circumvent the misinterpretation of DSC data.
\end{abstract}

Keywords DSC $\cdot$ Factor analysis $\cdot$ Compatibility $\cdot$ Incompatibility $\cdot$ Theophylline $\cdot$ Excipients

\section{Introduction}

Preformulation is a crucial phase in drug development in which the physicochemical profiling of active pharmaceutical ingredients (APIs) and excipients is determined and prototype formulations made. Since the performance of a solid dosage form is dependent on the physicochemical properties of API and excipients, the identification of suitable excipients is an important step. Concomitant with the choice of excipients is an API-excipient compatibility study [1].

Numerous approaches have been proposed which satisfy the API-excipient compatibility test [2]. Nonetheless, thermal methods of analysis, i.e., differential scanning calorimetry (DSC), differential thermal analysis (DTA) and thermogravimetry (TG), have been widely used for decades in compatibility studies of APIs with excipients [1].

Conventional compatibility testing methods require both multiple sample preparation and long storage times in order

Barbara Rojek

rojekb@gumed.edu.pl

1 Department of Analytical Chemistry, Medical University of Gdansk, Gen. J. Hallera 107, 80-416 Gdańsk, Poland to obtain reliable results. Thermal methods, however, potentially offer advantages over conventional isothermal stress testing (IST) techniques. Thermal analysis eliminates the need for lengthy storage conditions and for analytical method development for all the APIs required during IST. Additionally, thermal analysis allows a large number of excipient screening experiments to be performed over a short period. The results obtained from thermal techniques are direct indicators of those excipients which are likely to be compatible, reducing the preparation of conventional compatibility samples, thereby saving valuable time [3].

Of the thermal methods, DSC is the first choice technique applied to rapid screening of incompatibility in pharmaceutical mixtures, taking into account the appearance or disappearance of DSC peaks, their shifting to lower or higher temperatures, and the variations in their corresponding enthalpy of transition $(\Delta H)$. Thus, the main benefit of DSC is its speed in the selection of potential excipients to be used in the formulation process of new solid dosage forms. Still, conclusions based solely on DSC results may be misleading at times, probably due to the fact that DSC experiments are carried out at higher temperatures (up to $300{ }^{\circ} \mathrm{C}$ ) without light or moisture [4]. 
Furthermore, after the binary mixing of two ingredients, shifts in the transition temperature and peak shape and area invariably occur without necessarily representing a harmful interaction, so these changes need to be carefully evaluated [5]. Moreover, in the case of APIs that decompose without melting, omeprazole sodium for example, the search for incompatibility is problematic [6]. So the application of an unsupervised, multivariate statistical approach to improve the interpretation of DSC curves in the context of predicting the incompatibility in pharmaceutical mixtures is highly recommended.

Classification methods such as factor analysis (FA) are the most well known of the unsupervised multivariate statistical techniques. FA is a multivariate technique used to describe the relationships between different variables under study. These relationships are explained by new variables termed "factors," where the number of factors is less than the number of original objects. FA works efficiently and produces fewer factors to describe the relationship if the variables in question are highly correlated. For instance, if all of the variables in one group show high correlation among themselves and little with the variables in the remaining groups, each group can represent one factor [7]. Our preliminary study revealed that FA makes it possible to detect incompatibility in pharmaceutical mixtures based on FTIR and TG data [8].

Taking all the above into consideration, the objective of this work was to test the usefulness of FA as a supplementary approach to improve the interpretation of DSC data in order to predict incompatibility between API and excipients. Theophylline (Fig. 1) was used as a model API, while arabic gum, glicocol, glucose, microcrystalline cellulose PH 101, sorbitol and sucrose were selected as excipients.

\section{Experimental}

\section{Chemicals}

Theophylline with purity $\geq 98 \%$ and m.p. $271-273{ }^{\circ} \mathrm{C}$ was purchased from Fluka, Siegen, Germany. Arabic gum
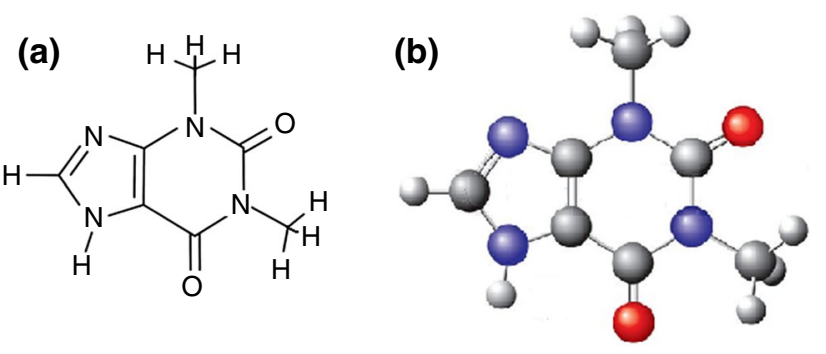

Fig. 1 Chemical structure (a) and ball- and stick model (b) of theophylline (acacia gum), glicocol (glycine, aminoacetic acid), sorbitol and sucrose were obtained from POCh, Gliwice, Poland. Microcrystalline cellulose PH 101 was provided by the FMC Corp. Europe N.V., Brussels, Belgium. Glucose was supplied by the Centro-Chem, Lublin, Poland. All substances were used as received without further purification.

\section{Sample preparation}

Binary mixtures of theophylline with excipients at 9:1, 7:3, $1: 1,3: 7$ and 1:9 (the first number of the ratio determines the content of theophylline in the mixtures) molar or mass ratios were obtained by gently mixing both components in an agate mortal for $5 \mathrm{~min}$ with a plastic spatula. For ingredients of similar molar mass mixtures were prepared at the molar ratios: theophylline with glicocol, glucose, sorbitol and sucrose. In contrast, for mixtures in which theophylline and excipient have significantly different molar mass, arabic gum and microcrystalline cellulose were prepared at the mass ratios.

\section{Differential scanning calorimetry (DSC)}

DSC measurements were taken out using a Mettler Toledo DSC 822e instrument (Schwerzenbach, Switzerland) with STARe software. All data were collected under dynamic nitrogen atmosphere $\left(70 \mathrm{~mL} \mathrm{~min}{ }^{-1}\right)$ in pierced flat-bottomed aluminum pans of $40 \mu \mathrm{L}$ (sample mass about $5 \mathrm{mg}$ ) and heating rate of $10{ }^{\circ} \mathrm{C} \mathrm{min}-1$ in the range from 20 to $300{ }^{\circ} \mathrm{C}$. The DSC was calibrated using indium (m.p. $156.6^{\circ} \mathrm{C}, \Delta H_{\mathrm{f}}=28.45 \mathrm{~J} \mathrm{~g}^{-1}$ ) and zinc (m.p. $419.6^{\circ} \mathrm{C}$, $\left.\Delta H_{\mathrm{f}}=107.50 \mathrm{~J} \mathrm{~g}^{-1}\right)$.

\section{Multivariate statistics}

Factor analysis was conducted using Statistica 10 software (StatSoft Inc., Tulsa, OK, USA), after which a data matrix consisting of variables and objects was constructed. For FA calculations, DSC parameters such as enthalpies, onset temperatures, peak temperatures, peak heights and peak widths were selected, these parameters being considered variables. The samples analyzed, such as theophylline, excipients and their mixtures at ratios of 9:1, 7:3, 1:1, 3:7 and 1:9, were deemed objects. FA calculations were performed separately for each excipient mixture.

\section{Results and discussion}

According to the procedure adopted for the compatibility study, the DSC curves of ingredients alone are compared to the curves obtained for physical mixtures at different ratios. It is assumed that the thermal properties of mixtures 
(melting point, change in enthalpy, etc.) are the sum of some individual ingredients if compatible. Incompatibility is indicated by a significant shift in the melting and disappearance of characteristic peaks of the ingredients, their absence, or the appearance of a new exo/endothermic peak and/or variation in the corresponding enthalpies of reaction in the physical mixture [3].

Solid-state reactions can occur in drugs and formulations, possibly initiating alterations in their stability, solubility, dissolution rates and bioavailability. Therefore, compatibility studies are necessary to ensure that potential physical and chemical interactions between API and excipient do not compromise drug stability [5].

The results of DSC investigation of theophylline mixtures with excipients and ingredients alone are given in Tables 1 and 2 and presented graphically in Figs. 2-7. Tables 1 and 2 summarize peak point, temperature onset, heat of fusion, and peak height and width. The DSC features selected for these tables are the most prominent in the DSC curve, and thus potentially most appropriate for compatibility studies. Detailed inspection of these data indicates that theophylline melted at $273.14{ }^{\circ} \mathrm{C}$, with the $T_{\text {onset }}$ at $272.35{ }^{\circ} \mathrm{C}$ and $\mathrm{a}-204.32 \mathrm{~J} \mathrm{~g}^{-1}$ heat of fusion. The DSC curve for theophylline (Figs. 2a-7a) displayed only a strong and somewhat narrow endothermal peak (peak height $9.73 \mathrm{~W} \mathrm{~g}^{-1}$ and peak width $2.59{ }^{\circ} \mathrm{C}$ ) indicating its melting. The literature data demonstrate that theophylline melts at $268{ }^{\circ} \mathrm{C}$ [9] or $269-274{ }^{\circ} \mathrm{C}$ [10], $270-274{ }^{\circ} \mathrm{C}$ [11]. In the case of the DSC curve of sorbitol (Fig. 6g), a narrow high peak can also be observed related to the melting of sorbitol at $100.67{ }^{\circ} \mathrm{C}$, with $T_{\text {onset }}$ at $97.67{ }^{\circ} \mathrm{C}, \quad \Delta H_{\text {fusion }}-170.69 \mathrm{~J} \mathrm{~g}^{-1}$, peak height at $6.41 \mathrm{~W} \mathrm{~g} \mathrm{~g}^{-1}$ and peak width $3.15^{\circ} \mathrm{C}$. The literature proves that the melting point of gamma polymorph of sorbitol is $97.78{ }^{\circ} \mathrm{C}$ or for the anhydrous form $110-112.8^{\circ} \mathrm{C}$ and the metastable form $93.8{ }^{\circ} \mathrm{C}$ [12]. The DSC curve of glicocol
(Fig. 4g) shows one slightly broader endothermic peak (peak height $17.80 \mathrm{~W} \mathrm{~g}^{-1}$ and peak width $8.08^{\circ} \mathrm{C}$ ) at $256.08{ }^{\circ} \mathrm{C}$ with $T_{\text {onset }}$ at $252.12{ }^{\circ} \mathrm{C}$ and heat fusion equal to $-967.34 \mathrm{~J} \mathrm{~g}^{-1}$. Glicocol undergoes melting with decomposition. According to the literature, glicocol melts with decomposition at $232-236{ }^{\circ} \mathrm{C}$ [12] or $262{ }^{\circ} \mathrm{C}$ [9].

The DSC curves of glucose (Fig. $5 \mathrm{~g}$ ) or sucrose (Fig. $7 \mathrm{~g}$ ) show three endothermic effects, two of which are most visible. These events are associated with melting, caramelization and decomposition. Prominent in the DSC curve of glucose (Fig. $5 \mathrm{~g}$ ) is the melting point at $162.29{ }^{\circ} \mathrm{C}$ with temperature onset at $158.84{ }^{\circ} \mathrm{C}$ and $\Delta H_{\text {fusion }}$ equaling $-191.40 \mathrm{~J} \mathrm{~g}^{-1}$. The second endothermic peak can be found at $217.38{ }^{\circ} \mathrm{C}$ with heat fusion equal to $-190.74 \mathrm{~J} \mathrm{~g}^{-1}$, attributed to the caramelization and decomposition of glucose. A literature review shows that glucose melts at $146{ }^{\circ} \mathrm{C}$ [9] or $147{ }^{\circ} \mathrm{C}$ [10] and undergoes decomposition above $200{ }^{\circ} \mathrm{C}$ [13]. When simple sugars are heated at high temperatures, the thermal degradation of sugars may occur through caramelization, this being the common name for a group of reactions that occur when carbohydrates are exposed to high temperatures [14].

In the case of the DSC curve of sucrose (Fig. $7 \mathrm{~g}$ ), the melting point is visible at $190.72{ }^{\circ} \mathrm{C}, T_{\text {onset }}$ at $188.83{ }^{\circ} \mathrm{C}$ and $\Delta H_{\text {fusion }}$ equaling $-125.01 \mathrm{~J} \mathrm{~g}^{-1}$. According to the literature, the melting of sucrose with decomposition takes place at $160-186^{\circ} \mathrm{C}[12]$. The second endothermic event at $226.84{ }^{\circ} \mathrm{C}$ is most likely derives from the caramelization and decomposition of sucrose. The DSC curve of arabic gum (Fig. 2g) or cellulose (Fig. 3g) presents a broad endothermic peak connected with dehydration. At temperatures above $200{ }^{\circ} \mathrm{C}$ these substances are decomposed. The literature data [12] do report that cellulose chars at 260-270 ${ }^{\circ} \mathrm{C}$, but no information about arabic gum has yet been uncovered.
Table 1 DSC parameters obtained for API and excipients

\begin{tabular}{lrrrcr}
\hline Substances & $T_{\text {onset }}{ }^{\circ} \mathrm{C}$ & $T_{\text {peak }}{ }^{\circ} \mathrm{C}$ & $\Delta H_{\text {fusion }} / \mathrm{J} \mathrm{g}^{-1}$ & Peak height $/ \mathrm{W} \mathrm{g}^{-1}$ & Peak width $/{ }^{\circ} \mathrm{C}$ \\
\hline Theophylline & 272.35 & 273.14 & -204.32 & 9.73 & 2.59 \\
Arabic gum & 25.01 & 106.22 & -1027.75 & 1.03 & 205.01 \\
& 268.08 & 308.74 & 133.37 & 0.25 & 22.66 \\
Microcrystalline cellulose & 72.52 & 93.78 & -193.02 & 0.37 & 99.89 \\
& 326.51 & 341.88 & $-185,90$ & 0.22 & 1.84 \\
Glicocol & 252.12 & 256.08 & -967.34 & 17.80 & 8.08 \\
Glucose & 58.45 & 65.65 & -2.50 & $49.38 \mathrm{e}^{-0.3}$ & 8.25 \\
& 158.84 & 162.29 & -191.40 & 6.21 & 4.13 \\
& 205.70 & 217.38 & -190.74 & 1.11 & 25.93 \\
Sorbitol & 97.67 & 100.67 & -170.69 & 6.41 & 3.15 \\
Sucrose & 188.83 & 190.72 & -125.01 & 5.28 & 3.25 \\
& 203.13 & 213.11 & -5.44 & $99.01 \mathrm{e}^{-0.3}$ & 8.86 \\
& 220.42 & 226.84 & -140.36 & 1.31 & 15.60
\end{tabular}


Table 2 DSC parameters obtained for theophylline mixtures with excipients

\begin{tabular}{|c|c|c|c|c|c|}
\hline Mixtures & $T_{\text {onset }} /{ }^{\circ} \mathrm{C}$ & $T_{\text {peak }} /{ }^{\circ} \mathrm{C}$ & $\Delta H_{\text {fusion }} / \mathrm{J} \mathrm{g}^{-1}$ & Peak height/W $\mathrm{g}^{-1}$ & Peak width $/{ }^{\circ} \mathrm{C}$ \\
\hline \multicolumn{6}{|c|}{ Theophylline-arabic gum } \\
\hline $9: 1$ & 268.04 & 270.35 & -142.99 & 5.72 & 3.09 \\
\hline \multirow{2}{*}{$7: 3$} & 58.54 & 110.95 & -89.07 & 0.20 & 71.62 \\
\hline & 262.37 & 268.21 & -118.50 & 2.06 & 5.33 \\
\hline \multirow[t]{2}{*}{$1: 1$} & 29.80 & 84.11 & -143.09 & 0.34 & 65.57 \\
\hline & 242.66 & 265.46 & -101.10 & 0.94 & 17.23 \\
\hline \multirow[t]{2}{*}{$3: 7$} & 27.40 & 93.56 & -266.72 & 0.55 & 76.91 \\
\hline & 237.53 & 256.48 & -82.68 & 0.59 & 21.85 \\
\hline \multirow[t]{2}{*}{$1: 9$} & 49.01 & 100.22 & -253.14 & 0.57 & 70.14 \\
\hline & 234.16 & 248.10 & -49.46 & 0.35 & 22.20 \\
\hline \multicolumn{6}{|c|}{ Theophylline-microcrystalline cellulose } \\
\hline $9: 1$ & 271.11 & 272.55 & -143.45 & 8.04 & 2.70 \\
\hline $7: 3$ & 270.12 & 273.03 & -114.66 & 4.19 & 4.40 \\
\hline $1: 1$ & 269.55 & 272.05 & -79.50 & 3.39 & 3.36 \\
\hline \multirow[t]{2}{*}{$3: 7$} & 54.14 & 107.61 & -68.87 & 0.17 & 65.09 \\
\hline & 269.00 & 271.75 & -44.77 & 2.02 & 3.03 \\
\hline \multirow[t]{2}{*}{$1: 9$} & 65.85 & 111.45 & -61.06 & 0.17 & 58.86 \\
\hline & 267.85 & 270.18 & -11.93 & 0.54 & 2.36 \\
\hline \multicolumn{6}{|c|}{ Theophylline-glicocol } \\
\hline \multirow[t]{2}{*}{$9: 1$} & 249.30 & 256.09 & -29.46 & 0.68 & 6.88 \\
\hline & 267.32 & 270.25 & -110.88 & 4.88 & 3.15 \\
\hline $7: 3$ & 252.14 & 260.04 & -281.90 & 4.38 & 9.77 \\
\hline $1: 1$ & 253.40 & 258.90 & -400.31 & 7.60 & 7.25 \\
\hline $3: 7$ & 252.63 & 258.47 & -575.40 & 10.18 & 8.25 \\
\hline $1: 9$ & 251.14 & 257.14 & -796.13 & 15.34 & 7.48 \\
\hline \multicolumn{6}{|c|}{ Theophylline-glucose } \\
\hline \multirow[t]{4}{*}{$9: 1$} & 155.93 & 160.84 & -15.24 & 0.47 & 4.83 \\
\hline & 234.71 & 236.15 & -5.62 & 0.43 & 1.80 \\
\hline & 247.40 & 248.02 & -3.54 & 0.60 & 0.86 \\
\hline & 262.27 & 267.73 & -114.38 & 3.18 & 4.68 \\
\hline \multirow[t]{2}{*}{$7: 3$} & 155.37 & 160.76 & -57.57 & 1.53 & 5.38 \\
\hline & 218.77 & 256.15 & -121.68 & 1.04 & 11.47 \\
\hline \multirow[t]{2}{*}{$1: 1$} & 155.06 & 159.70 & -102.34 & 3.17 & 4.64 \\
\hline & 199.25 & 227.63 & -196.79 & 0.79 & 39.70 \\
\hline \multirow[t]{2}{*}{$3: 7$} & 155.58 & 159.45 & -139.13 & 4.70 & 4.14 \\
\hline & 170.79 & 227.95 & -224.76 & 1.01 & 31.76 \\
\hline \multirow[t]{2}{*}{$1: 9$} & 154.93 & 159.24 & -166.94 & 4.98 & 4.77 \\
\hline & 225.48 & 232.55 & -219.46 & 1.22 & 26.35 \\
\hline \multicolumn{6}{|c|}{ Theophylline-sorbitol } \\
\hline \multirow[t]{2}{*}{$9: 1$} & 95.04 & 99.25 & -14.51 & 0.54 & 3.65 \\
\hline & 254.49 & 263.64 & -143.72 & 1.90 & 8.08 \\
\hline \multirow[t]{2}{*}{$7: 3$} & 95.49 & 99.74 & -51.96 & 1.67 & 4.26 \\
\hline & 230.88 & 243.15 & -90.93 & 0.60 & 25.79 \\
\hline \multirow[t]{2}{*}{$1: 1$} & 94.61 & 99.97 & -81.59 & 2.21 & 5.38 \\
\hline & 223.80 & 230.84 & -63.00 & 0.39 & 23.54 \\
\hline $3: 7$ & 96.03 & 99.68 & -119.33 & 4.18 & 3.53 \\
\hline $1: 9$ & 96.47 & 99.36 & -160.20 & 6.23 & 3.11 \\
\hline \multicolumn{6}{|c|}{ Theophylline-sucrose } \\
\hline $9: 1$ & 181.48 & 185.44 & -21.26 & 0.53 & 6.45 \\
\hline & 254.07 & 268.16 & -122.80 & 1.68 & 8.15 \\
\hline
\end{tabular}


Table 2 continued

\begin{tabular}{llcccc}
\hline Mixtures & $T_{\text {onset }} /{ }^{\circ} \mathrm{C}$ & $T_{\text {peak }} /{ }^{\circ} \mathrm{C}$ & $\Delta H_{\text {fusion }} / \mathrm{J} \mathrm{g}^{-1}$ & Peak height $/ \mathrm{W} \mathrm{g}^{-1}$ & Peak width $/{ }^{\circ} \mathrm{C}$ \\
\hline $7: 3$ & 181.96 & 186.19 & -63.48 & 1.39 & 7.76 \\
& 228.22 & 231.60 & -143.30 & 0.93 & 21.33 \\
$1: 1$ & 182.17 & 187.39 & -82.67 & 2.03 & 6.88 \\
& 223.24 & 226.45 & -114.66 & 0.78 & 22.22 \\
$3: 7$ & 181.55 & 186.41 & -107.44 & 2.76 & 6.58 \\
& 199.42 & 209.76 & -2.98 & $46.18 \mathrm{e}^{-0.3}$ & 10.92 \\
& 213.54 & 231.11 & -120.72 & 0.88 & 19.79 \\
$1: 9$ & 184.09 & 188.63 & -121.72 & 3.25 & 5.67 \\
& 220.05 & 228.52 & -126.94 & 1.21 & 15.38 \\
\hline
\end{tabular}

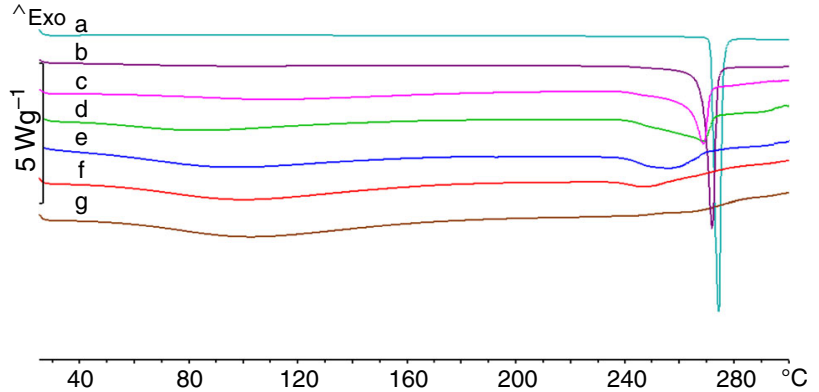

Fig. 2 DSC curves of a theophylline, $\mathbf{g}$ arabic gum and their mixtures at API/excipient ratios b 9:1, c 7:3, d 1:1, e 3:7, f $1: 9$

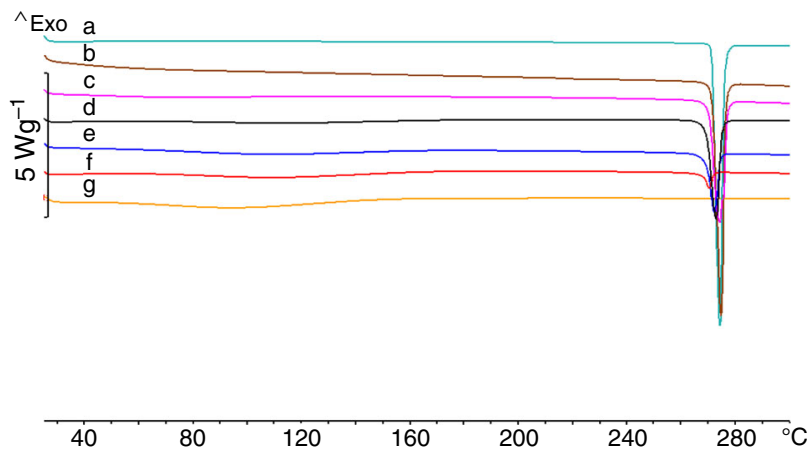

Fig. 3 DSC curves of a theophylline, $\mathbf{g}$ microcrystalline cellulose and their mixtures at API/excipient ratios b 9:1, c 7:3, d 1:1, e 3:7, f 1:9

The DSC results for binary mixtures of theophylline with excipients are presented graphically in Figs. $2-7$ and summarized in Table 2. The DSC curves of physical mixtures of theophylline with arabic gum (Fig. 2), with the exception of the 9:1 mixture, display two endothermic events. However, only the DSC curves of 9:1 and 7:3 theophylline mixtures with arabic gum show a slightly shifted and reduced melting point of theophylline, which probably overlapped with the second peak of arabic gum. Otherwise for theophylline mixtures with microcrystalline cellulose (Fig. 3), the melting point of theophylline occurs at the same temperature as the peak of theophylline alone (Table 2). Only the intensity of the theophylline peak on DSC curves of mixtures changes proportionately to theophylline content in these mixtures.

As illustrated in Fig. 4, a shifted melting point of theophylline can be found only on the DSC curve of the 9:1 mixture with glicocol. Furthermore, the melting point of theophylline may not be presented on the DSC curves of the remaining mixtures (Fig. $4 \mathrm{c}-\mathrm{f}$ ) or, alternatively, may overlap with the glicocol peak. Theophylline has a melting point close to that of glicocol. In the case of mixtures with glucose (Fig. 5), only the DSC curves of 9:1 and 7:3 mixtures (Fig. 5b, c) show a distorted, broadened, shifted theophylline peak, reduced about three and tenfold. Moreover, on the DSC curves of the remaining mixtures with glucose, the melting point of theophylline disappears.

In conformity with Table 2 and Fig. 6, the DSC results of theophylline mixtures with sorbitol reveal the lack of melting point of theophylline on the DSC curves of mixtures. Only on the DSC curve of 9:1 mixture is the changed, broadened, shifted and decreased peak of theophylline visible. In the case of mixtures with sucrose (Fig. 7), a situation similar to that with sorbitol mixtures is observable.

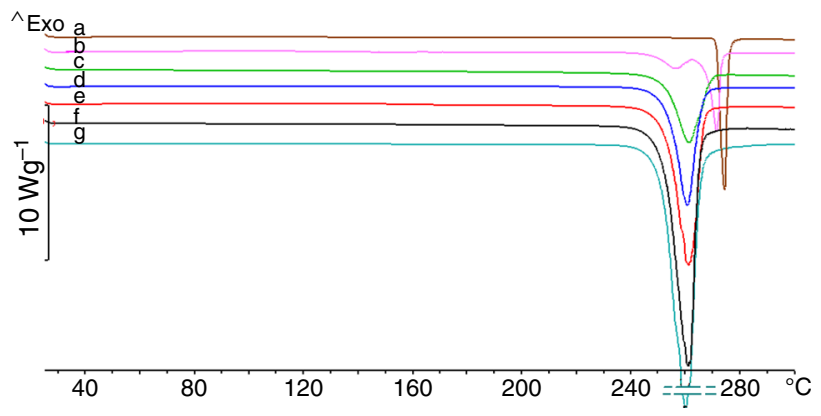

Fig. 4 DSC curves of a theophylline, $\mathbf{g}$ glicocol and their mixtures at API/excipient ratios b 9:1, c 7:3, d 1:1, e 3:7, f 1:9 


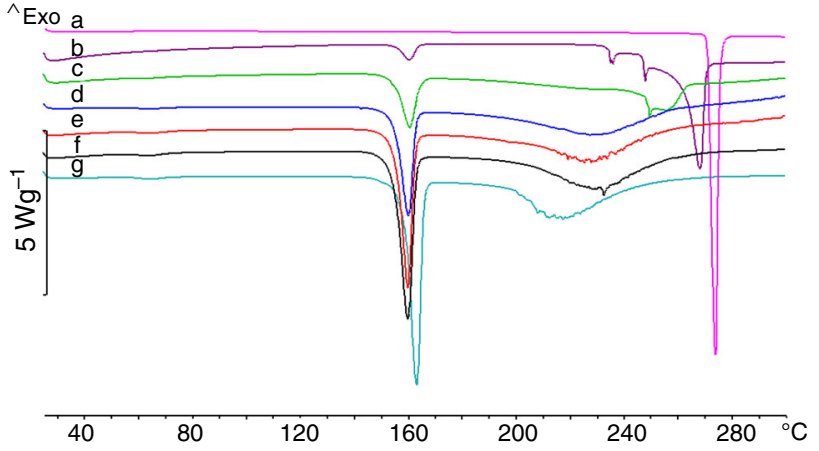

Fig. 5 DSC curves of a theophylline, $\mathbf{g}$ glucose and their mixtures at API/excipient ratios b 9:1, c 7:3, d 1:1, e 3:7, f $1: 9$

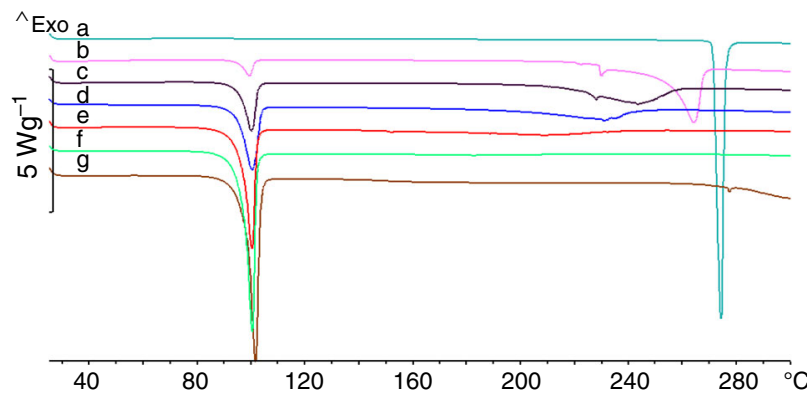

Fig. 6 DSC curves of a theophylline, $\mathbf{g}$ sorbitol and their mixtures at API/excipient ratios b 9:1, c 7:3, d 1:1, e 3:7, f 1:9

The DSC showed that in some cases, it is difficult to indicate compatibility or incompatibility between mixture ingredients, e.g., theophylline mixtures with glicocol or arabic gum. In such situations, multivariate statistics may be helpful and indeed decisive. FA is useful for studies that involve anything from a mere few to hundreds of variables, items from measurements or a series of tests. These variables can be reduced to a smaller set, in order to give a basic concept and to facilitate interpretation $[8,15]$.

The values of variance in the FA data for matrices created in this study, which consist of theophylline, excipient and their mixtures, are listed in Table 3. Factor 1 (F1) and factor 2 (F2) when taken together explained more

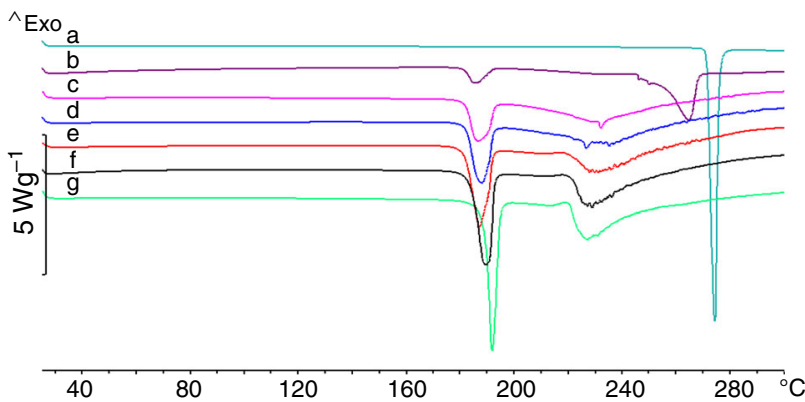

Fig. 7 DSC curves of a theophylline, $\mathbf{g}$ sucrose and their mixtures at API/excipient ratios b 9:1, c 7:3, d 1:1, e 3:7, f 1:9 than $87 \%$ of the total variance. Consequently, the results of FA can be visualized on a two-dimensional score scatter plot. The localization of both ingredients and their mixtures on the FA plot indicates compatibility or incompatibility. If the API with mixtures at highest content and the 1:1 mixture form a separate cluster and the other cluster consists of excipient with mixtures with its highest content; this indicates that compatibility between ingredients is evident. By contrast, the other distribution of samples, e.g., API, excipient and some mixtures, is grouped in one cluster with remaining mixtures in the other. This reveals differences in the thermal properties of the samples from one or the other cluster.

Figure 8 presents the score plot for the first two factors (F1 and F2) for theophylline, microcrystalline cellulose and their mixtures. In this case, the first two factors account for more than $90 \%$ of the total variance (Table 3). As can be seen from Fig. 8, theophylline with its mixtures at ratios 9:1, 7:3 and 1:1 forms a cluster on the left-hand side of the FA score plot. Localization of theophylline and its mixtures in one cluster indicates the high similarities of the DSC curves of mixtures to the DSC curve of theophylline, which can be observed in Fig. 3. The DSC curves showed a characteristic peak of theophylline (Fig. 3b-d), but the height of this peak depends on the theophylline content in a mixture and decreases proportionally as its content in the mixture is lowered.

The second cluster on the right of the plot includes microcrystalline cellulose and the remaining mixtures. This cluster could be divided into two smaller ones: the first is composed of microcrystalline cellulose and the second consists of two mixtures at the ratios of 3:7 and 1:9. The DSC curves of these mixtures (Fig. 3e, f) display low similarity to the DSC curve of theophylline (Fig. 3a) due to the lowest theophylline content. Hence, these mixtures are more similar to the DSC curve of microcrystalline cellulose (Fig. 3g). On the other hand, their distribution in the cluster indicates that they differ from microcrystalline cellulose.

Concluding, all of the samples grouped in each distinct cluster within these larger clusters exhibit similar thermal properties. This grouping of samples indicates compatibility between ingredients.

The next example of the clustering tendency of samples is depicted in Fig. 9 for theophylline, sorbitol and their mixtures. In this case, F1 and F2 taken together explained more than $87 \%$ of the total variance. The first cluster, again on the left-hand side of the FA score plot, is formed by three mixtures at the ratios of 9:1, 7:3 and 1:1. Localization of three mixtures in the first cluster indicates the lack of similarity of their DSC curves (Fig. 6b-d) to the curves of ingredients (Fig. 6a, g). In addition, only the mixtures with the highest theophylline content are found in this cluster. 
Table 3 The variances calculated by FA for theophylline mixtures

\begin{tabular}{llllc}
\hline Matrices & Theophylline mixtures & $\begin{array}{l}\text { Factor 1 } \\
\text { variance/\% }\end{array}$ & $\begin{array}{l}\text { Factor 2 } \\
\text { variance/\% }\end{array}$ & $\begin{array}{l}\text { Factor 3 } \\
\text { variance/\% }\end{array}$ \\
\hline 1 & Arabic gum & 73.83 & 19.99 & 4.51 \\
2 & Microcrystalline cellulose & 66.52 & 23.54 & 8.03 \\
3 & Glicocol & 60.62 & 29.68 & 8.98 \\
4 & Glucose & 71.17 & 21.89 & 4.23 \\
5 & Sorbitol & 70.83 & 16.74 & 10.70 \\
6 & Sucrose & 83.65 & 8.78 & 6.70 \\
\hline
\end{tabular}

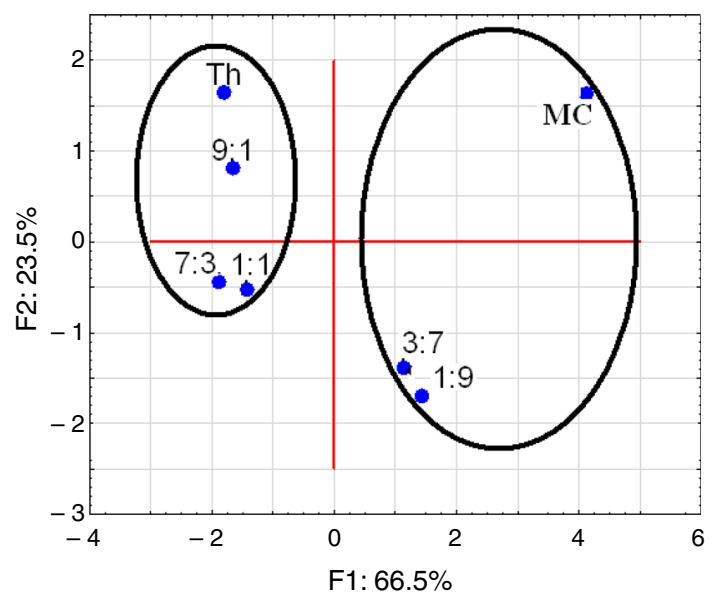

Fig. 8 FA score scatter plot for DSC data: theophylline (Th), microcrystalline cellulose (MC) and their mixtures at the ratios: $9: 1,7: 3,1: 1,3: 7,1: 9$

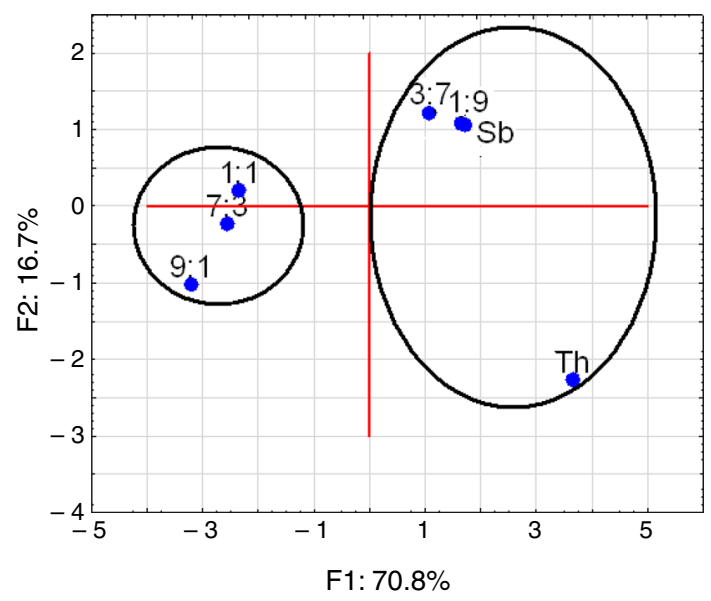

Fig. 9 FA score scatter plot for DSC data: theophylline (Th), sorbitol $(\mathrm{Sb})$ and their mixtures at the ratios: 9:1, 7:3, 1:1, 3:7, 1:9

The remaining mixtures and both ingredients (theophylline and sorbitol) create a second cluster on the righthand side of the plot. This cluster can be divided into two smaller ones: the first is composed of mixtures at the ratios of 3:7 and 1:9 and sorbitol, and the second consists of theophylline. The DSC curves of these mixtures (Fig. 6e, f) are very similar to the curve of sorbitol; there is a characteristic peak of sorbitol. Grouping of theophylline, sorbitol and their mixtures at the ratios of 3:7 and 1:9 along the F2 axis indicates the high dissimilarity between the DSC curves of theophylline (Fig. 6a) and mixtures (Fig. 6e, f). This means that the DSC curve of theophylline has only a similar "segment" to the curves of sorbitol and mixtures at the ratios of 3:7 and 1:9. The clustering of samples in this manner indicates incompatibility between ingredients.

Finally, DSC investigations supported by FA (Table 4) revealed incompatibility in mixtures of theophylline with arabic gum, glucose, sorbitol and sucrose, as revealed by the formation of distinctly separated clusters on the FA score scatter plots. One cluster usually contained some theophylline mixtures with excipient; the other consisted of the remaining mixtures, theophylline and excipient.

Application of FA as a tool supporting the interpretation of DSC data allows to unambiguous detection of incompatibility. In the case of theophylline mixtures with arabic gum (Fig. 2), it was difficult to unequivocally predict the incompatibility, because the DSC curves of some mixtures showed peak originates from theophylline. In the case of mixtures at the ratios 9:1 and 7:3, this peak is slightly shifted to lower temperatures. For the remaining mixtures, the peak is expanded and fuzzy. Based on the FA calculations, it was ultimately concluded that theophylline is incompatible with arabic gum.

Arabic gum is a complex mixture of glycoproteins and polysaccharides predominantly consisting of arabinose and galactose [16]. Moreover, this material usually contains oxidizing enzymes-oxidases and peroxidases [17]. According to Janicki et al. [18], arabic gum enzymes cause incompatibility between vitamin A and bismuth nitrate.

The DSC curves of theophylline mixtures with glicocol (Fig. 4c-f) revealed that the melting peak of theophylline is slightly shifted and overlapped with the melting peak of glicocol. These overlapping peaks hindered the interpretation of DSC curves. FA calculations definitively demonstrated compatibility between theophylline and glicocol.

The FA also ultimately confirms the incompatibility of theophylline with glucose. The DSC peak due to melting of 
Table 4 Results obtained by using FA as supplementary tools for interpretation of the DSC data for theophylline mixtures

\begin{tabular}{lll}
\hline Matrices & Theophylline mixtures & Results of DSC supported by FA \\
\hline 1 & Arabic gum & Incompatibility \\
2 & Microcrystalline cellulose & Compatibility \\
3 & Glicocol & Compatibility \\
4 & Glucose & Incompatibility \\
5 & Sorbitol & Incompatibility \\
6 & Sucrose & Incompatibility \\
\hline
\end{tabular}

theophylline is observed only for mixture at the ratio of 9:1 (Fig. 5b), but its height does not reflect the theophylline content in this mixture. The DSC curves of the remaining mixtures (Fig. 5c-f) do not show the characteristic peak connected with the melting of theophylline.

The incompatibility of theophylline with glucose is probably owing to the Maillard reaction. The chemical change in the mixture results from an initial reaction of a reducing sugar, e.g., glucose, with an amino compound, followed by a cascade of consecutive and parallel reactions to form a variety of colored and colorless products which range from flavor volatiles (low molecular weight) to melanoidins (low and high molecular weight, brown, nitrogenous chromophores) [19].

As shown in Table 4, theophylline and sucrose are also incompatible, what was confirmed using FA calculations. Excluding the mixture with the highest content of theophylline (Fig. 7b), the DSC peak connected with melting of theophylline has not been observed for the remaining mixtures (Fig. 7c-f). The incompatibility may be due to the reaction of theophylline with products of sucrose caramelization. Caramelization is the process of sucrose decomposing to glucose and fructose, and finally to caramel (coloring substances) at temperatures close to its melting (approximately $185{ }^{\circ} \mathrm{C}$ ) [20].

In the case of sorbitol (an isomer of mannitol), the incompatibility with theophylline is probably due to the same mechanism as in the case of mannitol. Bharate et al. [21] reported that mannitol was incompatible with aminocontaining drugs, e.g., omeprazole, primaquine and quinapril. Furthermore, Stulzer et al. [22] indicated that interaction between API and mannitol can also be due to a hydrogen bond formation by nitrogen groups of piroxicam and $\mathrm{C}-\mathrm{H}$ and $\mathrm{CH}_{2}$ groups of mannitol.

\section{Conclusions}

The results of a DSC study of theophylline, excipients and binary physical mixtures at the ratios 9:1, 7:3, 1:1, 3:7 and 1:9 supported by chemometry factor analysis can successfully be employed for the detection of compatibility/ incompatibility. The examination of data acquired from
DSC with the aid of FA could be less ambiguous than that of data received from DSC scans. The results of FA calculations in the form of the two-dimensional score scatter plot revealing the compatibility of ingredients of pharmaceutical mixtures may be reflected by grouping together those mixtures with similar thermal properties. In this case, theophylline and mixtures with the highest API content create a cluster distinctly separate from the second, consisting of excipient and mixtures with high excipient content. By contrast, the second form of sample clustering confirms the incompatibility of ingredients. In conclusion, the results obtained from FA analysis of the DSC data successfully revealed the compatibility in theophylline mixtures with cellulose and glicocol.

Acknowledgements This research was funded by the Ministry of Science and Higher Education, Poland, Grant Number 02-0015/07/ 505 .

Open Access This article is distributed under the terms of the Creative Commons Attribution 4.0 International License (http://creative commons.org/licenses/by/4.0/), which permits unrestricted use, distribution, and reproduction in any medium, provided you give appropriate credit to the original author(s) and the source, provide a link to the Creative Commons license, and indicate if changes were made.

\section{References}

1. Adeyeye MCh, Brittain HG. Preformulation in solid dosage form development. New York: Informa Healthcare; 2008.

2. Kaur A, Goindi S, Katare OP. Thermal analysis and quantitative characterization of compatibility between diflunisal and lipid excipients as raw materials for development of solid lipid nanoparticles. Thermochim Acta. 2016;643:23-32.

3. Chadha R, Bhandari S. Drug-excipient compatibility screeningrole of thermoanalytical and spectroscopic techniques. J Pharm Biomed Anal. 2014;87:82-97.

4. Ding T, Chen L, Zhai LH, Fu Y, Sun BW. Compatibility study of rivaroxaban and its pharmaceutical excipients. J Therm Anal Calorim. 2017;130:1569-73.

5. da Silveira LM, Fiorot AB, Xavier TP, Yoshida MI, de Oliveira MA. Drug-excipient compatibility assessment of solid formulations containing meloxicam. Eur J Pharm Sci. 2018;112:146-51.

6. Veiga A, Oliveira PR, Bernardi LS, Mendes C, Silva MAS, Sangoi MS, Janissek PR, Murakami FS. Solid-state compatibility studies of a drug without melting point. The case of omeprazole sodium. J Therm Anal Calorim. 2018;131:3201-9. 
7. Alkarkhi AFM, Alqaraghuli WAA. Easy statistics for food science with R. London: Elsevier; 2019.

8. Rojek B, Wesolowski M. FTIR and TG analyses coupled with factor analysis in a compatibility study of acetazolamide with excipients. Spectrochim Acta A. 2019;208:285-93.

9. Book by multiple authors. Physicochemical guide. Warsaw: WNT; 1974.

10. Encyclopaedia of the technique. Chemistry. Warsaw: WNT; 1993.

11. Lund W. The pharmaceutical codex. 7th ed. London: Pharmaceutical Press; 2004.

12. Rowe RC, Sheskey PJ, Quinn ME. Handbook of pharmaceutical excipients. 6th ed. London: American Pharmaceutical Association, Pharmaceutical Press; 2009.

13. Şenocak A, Alkan C, Karadağ A. Thermal decomposition and a kinetic study of poly(para-substituted styrene)s. Am J Anal Chem. 2016;7:246-53.

14. Woo KS, Kim HY, Hwang IG, Lee SH, Jeon HS. Characteristics of the thermal degradation of glucose and maltose solutions. Prev Nutr Food Sci. 2015;20:102-9.

15. Yong AG, Pearce S. A beginner's guide to factor analysis: focusing on exploratory factor analysis. Tutor Quant Methods Psychol. 2013;9:79-94.
16. Klein M, Aserin A, Ishai PB, Garti N. Interaction between whey protein isolate and gum Arabic. Coll Surf B Biointerfaces. 2010;79:377-83.

17. Kohlmünzer S. Pharmacognosy: a handbook for pharmacy students. Warsaw: PZWL; 2003.

18. Janicki S, Fiebig A, Sznitowska M. Applied pharmacy: a handbook for pharmacy students. Warsaw: PZWL; 2008.

19. Martins SIFS, Boekel MAJS. A kinetic model for the glucose/ glycine Maillard reaction pathways. Food Chem. 2005;90:257-69.

20. Asadi M. Beet-sugar handbook. Hoboken: Wiley; 2007.

21. Bharate SS, Bharate SB, Bajaj AN. Interactions and incompatibilities of pharmaceutical excipients with active pharmaceutical ingredients: a comprehensive review. J Excip Food Chem. 2010;1:3-26.

22. Stulzer HK, Tagliari MP, Cruz AP, Silva MAS, Laranjeira MCM. Compatibility studies between piroxicam and pharmaceutical excipients used in solid dosage forms. Pharm Chem J. 2008;42:215-9.

Publisher's Note Springer Nature remains neutral with regard to jurisdictional claims in published maps and institutional affiliations. 